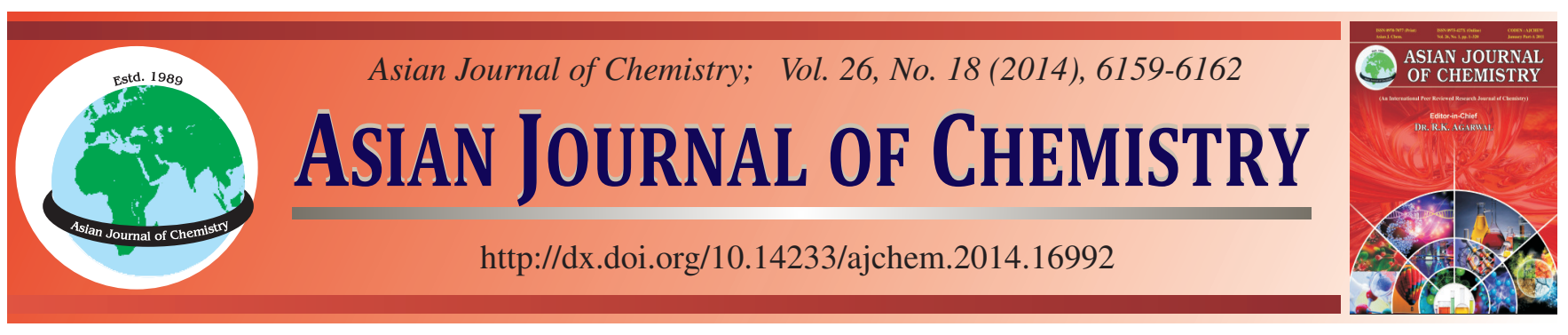

\title{
Synthesis, Characterization and Antimicrobial Potential of Novel Conjugated Schiff Bases
}

Ameer Fawad Zahoor ${ }^{1}$, Muhammad YousaF $^{1, *}$, Asim Mansha ${ }^{1}$, Shazia Naheed $^{1}$, Matloob Ahmad $^{1}$, Anbreen Anjum ${ }^{2}$, Kiran Aftab $^{1}$, Abdul Ghaffar $^{2}$, Sajuad Ahmad $^{3}$ and Ali Irfan ${ }^{1}$

\author{
${ }^{1}$ Department of Chemistry, Government College University, Faisalabad, Pakistan \\ ${ }^{2}$ Department of Applied Chemistry and Biochemistry, Government College University, Faisalabad, Pakistan \\ ${ }^{3}$ University of Engineering and Technology Lahore, Faisalabad Campus, Faisalabad, Pakistan
}

*Corresponding author: E-mail: dryousafsmor@gmail.com

\begin{abstract}
Anthracenylamine and naphthylamine were reacted with 1,3-cyclohexadienone and 1, 4-benzoquinone in order to prepare four $(\mathbf{1}, \mathbf{2}, \mathbf{3} \&$ 4) conjugated Schiff bases for the evaluation of their antibacterial as well as antifungal activities. The results of their activities were compared with standard drugs against three strains of bacteria as well as three strains of fungi and they showed that the Schiff base 4 $\left(\mathrm{C}_{34} \mathrm{H}_{22} \mathrm{~N}_{2} \mathrm{O}\right)$ exhibited good inhibition zones against all the strains of bacteria $(10.74 \pm 0.65,10 \pm 0.675,10.65 \pm 0.75 \mathrm{~mm})$ as well as fungi $(9.15 \pm 0.815,10.25 \pm 0.55,10.5 \pm 0.575 \mathrm{~mm})$ as compared to others $(\mathbf{1}, 2$ \& $\mathbf{3})$. The Schiff base $\mathbf{3}\left(\mathrm{C}_{26} \mathrm{H}_{24} \mathrm{~N}_{4}\right)$ showed better potential for $S$. aureus $(10 \pm 0.856 \mathrm{~mm})$ strain of bacteria and A. alternate $(10.5 \pm 2.150 \mathrm{~mm})$ strain of fungi. Its activity against other two strains of bacteria and fungi was also better than other two Schiff bases $(\mathbf{1} \& \mathbf{2})$. The Schiff base $\mathbf{2}\left(\mathrm{C}_{26} \mathrm{H}_{22} \mathrm{~N}_{2}\right)$ exhibited reasonable activity against $B$. subtilus $(10 \pm 0.715 \mathrm{~mm})$ and $A$. alternate $(8.55 \pm 0.015 \mathrm{~mm})$. The compound $(\mathbf{1})$ showed least antibacterial $(4.5 \pm 0.815,5 \pm$ $0.716,4.75 \pm 0.950 \mathrm{~mm})$ as well as antifungal $(4 \pm 0.575,4.15 \pm 0.570,6.5 \pm 1.725 \mathrm{~mm})$ activity. From the results it is concluded that delocalization of $\pi$ electrons has the positive influence on the antimicrobial potential of the titled Schiff bases. Thus these Schiff bases may serve as a basis for the chemical modifications directed towards the development of a new class of antibacterial agents.
\end{abstract}

Keywords: Conjugated Schiff base, Bacterial strains, Fungal strains, Activity.

\section{INTRODUCTION}

Nowadays, the increasing microbial resistance to antibiotics led the scientist to search for new compounds with potential effects against pathogenic bacteria. The most spectacular advances in medicinal chemistry have been made when heterocyclic compounds played an important role in regulating biological activities. Many Schiff bases are known to be medicinally important and are used to design medicinal compounds. Nitro and halo derivatives of Schiff bases are reported to have antitumor and antimicrobial activities ${ }^{1}$. Antifungal and antimicrobial activities of various Schiff bases have also been reported $^{2}$. Fungi toxicity of some Schiff bases has investigated by Sahu $e \mathrm{al}^{3}$. Similarly high antimicrobial activities of some Schiff bases were reported by Gawad et al ${ }^{4}$. Many Schiff bases are known to be medicinally important and are used to design medicinal compounds ${ }^{5}$. Cinnmaldehyde is a well-established natural antimicrobial compound. Several studies ${ }^{6}$ showed that the presence of a lone pair of electrons in a $s p^{2}$ hybridized orbital of nitrogen atom of the azomethine group is of considerable chemical and biological importance. Literature also justifies that Schiff bases are important class of compounds in medicinal field. They show biological applications including antibacterial, antifungal and antitumor activities ${ }^{7,8}$.

Latter it was found that antimicrobial agents reduce or completely block the growth and multiplication of bacteria and are helpful in the treatment of various infectious diseases like meningitis, malaria, tuberculosis, pneumonia, AIDS, etc. Schiff bases derived from aromatic amines and aromatic aldehydes have a wide variety of applications in many fields, for example, biological, inorganic and analytical chemistry 9 . Increase in the mortality rate associated with infectious diseases is directly related to bacteria that exhibit multiple resistance to antibiotics. The lack of effective treatments is the main cause of this problem. The development of new antibacterial agents with novel and more efficient mechanisms of action is definitely an urgent medical need. Keeping in mind the medicinal potential of Schiff bases, also assuming the bactericidal effects of anthracene and naphthalene, the novel conjugated Schiff bases were prepared by reacting 1,3-cyclohex-adione and 1,4benzoquinone with anthracenyl amine and naphthylamine for evaluating their antimicrobial potential. 
EXPERIMENTAL

Synthesis of $\mathbf{C}_{20} \mathbf{H}_{17} \mathbf{N O}(\mathbf{1})$ : A mixture of $7 \mathrm{mmol}(0.784$ g) 1,3-cyclohexadione and $7 \mathrm{mmol}(1.35 \mathrm{~g}) 2$-aminoanthracene along with $1 \mathrm{~mL}$ of glacial acetic acid and $70 \mathrm{~mL}$ of toluene was refluxed in $100 \mathrm{~mL}$ flask adjusted with a stirring system in an oil bath for $10 \mathrm{~h}$. After the said time, the resulting crude product was concentrated up to dryness. The impure product was washed twice with petroleum ether in order to remove the reactants if any. This washed product was subjected to column chromatography by using silica gel and petroleum ether-ethyl acetate (2:1) solvent system. The pure product was concentrated up to dryness using rotary evaporator, dried well under vacuum which yielded $59 \%$ orange yellow microcrystalline compound. The resulting Schiff base was subjected to mass spectrometry and elemental analysis prior to be tested for antimicrobial potential. The observed molecular mass was 286 while the calculated was 287 . Anal. $\mathrm{C}_{20} \mathrm{H}_{17} \mathrm{NO}(\%)$ Calcd.: C, 83.62; H, 5.92; N, 14.29. Found: C, 83.59; H, 5.88; N, 14.24.

Synthesis of $\mathbf{C}_{26} \mathbf{H}_{22} \mathbf{N}_{\mathbf{2}}$ (2): A mixture of 3 mmol (0.336 g) 1,3-cyclohexadione and $6 \mathrm{mmol}(0.858 \mathrm{~g}) 1$-aminonaphthalene along with $1 \mathrm{~mL}$ of glacial acetic acid and $70 \mathrm{~mL}$ of toluene were refluxed in $100 \mathrm{~mL}$ flask adjusted with a stirring system in an oil bath for $10 \mathrm{~h}$. After the said time, the resulting crude product was concentrated. The supernatant was poured out carefully and the residue was washed twice with petroleum ether in order to remove the reactants if any. The impure product was subjected to column chromatography by using silica gel and petroleum ether-ethyl acetate $(2: 1)$ solvent system. The solvent from the eluted pure product was removed by rotary evaporator, dried well under vacuum and yielded $56 \%$ yellow microcrystalline solid. The resulting Schiff base was subjected to mass spectrometry and then elemental analysis prior to be tested for antimicrobial potential. The observed molecular mass was 362.2 while the calculated was 362. Anal. $\mathrm{C}_{26} \mathrm{H}_{22} \mathrm{~N}_{2}$ (\%) Calcd.: C, 86.19; H, 6.08; N, 7.73 Found : C, 86.14; H, 6.04; N, 7..70.

Synthesis of $\mathrm{C}_{26} \mathrm{H}_{24} \mathrm{~N}_{\mathbf{4}}$ (3): Equimolar quantities of 1,3cyclohexadione ( $3 \mathrm{mmol}, 0336 \mathrm{~g}$ ) and 1,8-diaminonaphthalene ( $3 \mathrm{mmol}, 0.474 \mathrm{~g}$ ) along with $1 \mathrm{~mL}$ of glacial acetic acid and $70 \mathrm{~mL}$ of toluene were refluxed in $100 \mathrm{~mL}$ flask adjusted with a stirring system in an oil bath for $10 \mathrm{~h}$. After the said time, the resulting crude product was concentrated up to dryness using rotary evaporator. The impure product was washed twice with petroleum ether in order to remove the reactants if any. The washed crude product was subjected to column chromatography using silica gel and petroleum etherethyl acetate (2:1) solvent system. The eluted pure product was concentrated up to dryness using rotary evaporator, dried well under vacuum and yielded $55 \%$ pale yellow semi crystalline compound. The titled conjugated Schiff base was subjected to mass spectrometry and elemental analysis prior to be tested for antimicrobial activity. The observed molecular mass was 392 while the calculated was 392.2 (Fig. 1). Anal. $\mathrm{C}_{26} \mathrm{H}_{24} \mathrm{~N}_{4}(\%)$ Calcd.: C , 79.59; H, 6.12; N, 29.56. Found: C, 79.56; H, 6.09; N, 29.54.

Synthesis of $\mathrm{C}_{34} \mathrm{H}_{22} \mathbf{N}_{2} \mathrm{O}$ (4): Equimolar quantities of 1,4benzoquinone ( $5 \mathrm{mmol}, 0.540 \mathrm{~g}$ ) and 2-aminoanthracene
( $5 \mathrm{mmol}, 0.965 \mathrm{~g}$ ) along with $1 \mathrm{~mL}$ of glacial acetic acid and $70 \mathrm{~mL}$ of toluene were refluxed in $100 \mathrm{~mL}$ flask adjusted with a stirring system in an oil bath for $10 \mathrm{~h}$. After $10 \mathrm{~h}$, the resulting reaction mixture was concentrated up to dryness using rotary evaporator. The resulting crude product was washed twice with petroleum ether in order to remove the reactants. The washed impure product was subjected to column chromatography using silica gel and petroleum ether-ethyl acetate (2:1) solvent system. The eluted purified product was concentrated up to dryness using rotary evaporator, dried well under vacuum and yielded $57 \%$ orange yellow semi crystalline solid. The resulting Schiff base was subjected to mass spectrometric and then elemental analysis prior to tested for antimicrobial activity. The observed molecular mass was 474 while the calculated was 474.2 (Fig. 1). Anal. $\mathrm{C}_{34} \mathrm{H}_{2}{ }_{2} \mathrm{~N}_{2} \mathrm{O}$ (\%) Calcd.: C, 86.08; H, 4.64; N, 5.9. Found: C, 86.05; H, 4.61; N, 5.7.

Antimicrobial activity: Disc diffusion method was used to test the antibacterial and anti fungal activity. Different strains (bacterial and fungal strains) were engaged to check the antibacterial and antifungal activities.

Antibacterial activity: Three different strains of bacteria, Escherichia coli, Staphylococcus aureus and Bacillus subtilis were used to evaluate the antibacterial potential of these newly synthesized conjugated Schiff bases as compared with Rifamipicin as a standard one ${ }^{10}$. The experimental Schiff bases were employed for antibacterial potential evaluation using Disc diffusion method. Nutrient agar was mixed in distilled water and dispersed homogenously. Sterilization of the medium was carried out by means of autoclave at $121^{\circ} \mathrm{C}$ for $20 \mathrm{~min}$. Medium was treated with inoculums before it was transferred to petri plates. The filter paper discs were placed parallel on growth medium $(100 \mu \mathrm{L})$ containing said conjugated Schiff bases separately. The incubation of Petri plates was taken for $24 \mathrm{~h}$ at $37{ }^{\circ} \mathrm{C}$ for bacterial growth. The Schiff bases successfully inhibited differently the growth of bacteria and formed clear zones. Zone reader was employed to measure the inhibition zones in $\mathrm{mm}$. The results of all the experimental petri plates were compared with drug rifamipicin ${ }^{11}$.

Antifungal activity: Similarly three fungal strains, $A$. flavus, A. alternate and A. niger ${ }^{10}$ were used to evaluate the antifungal potential of said conjugated Schiff bases. The growth medium was synthesized, sterilized and then transferred to the petri plates. Filter paper discs were cited on growth medium. Appropriate fungal strain was transferred on the filter paper disc present in the growth medium containing Petri plate. The experimental Schiff bases were applied $(100 \mu \mathrm{L})$ separately on each disc and then petri plates were incubated for $48 \mathrm{~h}$ at $28^{\circ} \mathrm{C}$ for fungus growth. The Schiff bases inhibited the fungal growth differently. The results of all the experimental petri plates were compared with that of antifungal drug, fluconazol ${ }^{12}$.

\section{RESULTS AND DISCUSSION}

The 4 novel conjugated Schiff bases were prepared using literature procedure ${ }^{13}$ (Scheme-Ia, b).

After purification, all of these conjugated Schiff bases were subjected to mass spectrometry and elemental analysis prior to their antimicrobial potential evaluation. Since the compound (4) showed good antibacterial as well as antifungal 


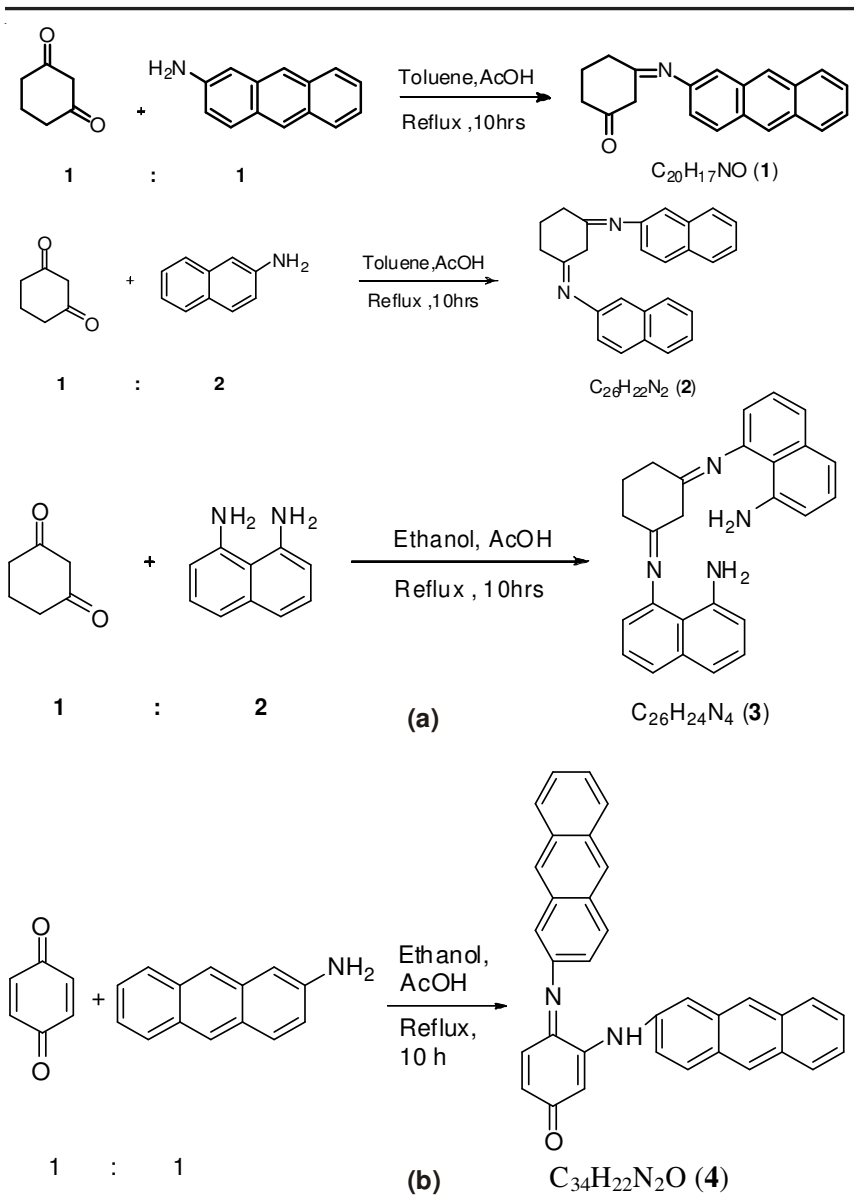

Scheme-I: (a) Synthesis of 1,3-cyclohexadione derivatives of conjugated Schiff base (b) Synthesis of 1,4-benzoquinone derivative of conjugated Schiff base

activities while the compound (3) exhibited comparatively better antimicrobial potential than the compounds (1) and (2), respectively.

Considering the antibacterial activity of the conjugated Schiff bases as compared with rifamipicin a standard drug, the results, as mean $\pm \mathrm{SD}$. (Table-1), explained that the $\mathrm{C}_{34} \mathrm{H}_{22} \mathrm{~N}_{2} \mathrm{O}$ conjugated Schiff base (4) exhibited good potential, $10.74 \pm 0.65,10 \pm 0.675,10.65 \pm 0.75 \mathrm{~mm}$ inhibiting zones, for all the three, Escherichia coli, Staphylococcus aureus and Bacillus subtilis, strains of bacteria as compared with other Schiff bases. Similarly the Schiff base (3) showed better efficiency as compared with Schiff base (2) and (1). It showed good, $10 \pm 0.856 \mathrm{~mm}$ inhibition, efficiency in case of $S$. aureus as compared with other two strains. The Schiff base (2) expressed better, $10 \pm 0.715 \mathrm{~mm}$, inhibition for $B$. subtilis bacteria while the $\mathrm{C}_{20} \mathrm{H}_{17} \mathrm{ON}$ Schiff base (1) exhibited least potential than other attempted conjugated Schiff bases. From the results it is clear that delocalization of $\pi$ electrons over the molecule play an important for the antibacterial activity of the titled compounds. Literature also explains that delocalizations of $\pi$ electrons over the whole molecule increases lipophilic character of the molecule and favor its permeation through lipid layer of the bacterial membranes. This increased lipophilic character of the molecule seems to be responsible for its enhanced antimicrobial activity. Such molecules may be suggested to deactivate various cellular enzymes which play vital role in various metabolic pathways of the microorganisms ${ }^{14}$.

\begin{tabular}{ccccc}
\multicolumn{5}{c}{ TABLE-1 } \\
ANTIBACTERIAL POTENTIAL DATA \\
OF CONJUGATED SCHIFF BASES
\end{tabular}

Similarly the antifungal activity of the experimental conjugated Schiff bases was compared with fluconazol drug as a standard one. The results as mean \pm SD (Table-2), explained that Schiff base (4) like antibacterial activity expressed good efficiency especially better $10.25 \pm 0.55,10.5 \pm 0.575 \mathrm{~mm}$ in case of A. flavous and A. alternate as compared with other attempted Schiff bases. Similarly the Schiff base (3) exhibited good, $10.5 \pm 2.150 \mathrm{~mm}$, inhibition for A. alternate fungi as compared with other tested strains of fungi. The overall efficiency was better than (2) and (1) Schiff bases. Likewise the Schiff base (2) exhibited satisfactory, $8.55 \pm 0.015 \mathrm{~mm}$, inhibition for A. alternate fungi as compared with other two strains. The overall its efficiency was better than Schiff base (1). In other words the Schiff base (1) exhibited least potential against all the tested strains of fungi as compared with the other three attempted conjugated Schiff bases.

\begin{tabular}{|c|c|c|c|c|}
\hline \multicolumn{5}{|c|}{$\begin{array}{l}\text { TABLE-2 } \\
\text { ANTIFUNGAL POTENTIAL DATA } \\
\text { OF CONJUGATED SCHIFF BASES }\end{array}$} \\
\hline \multirow[t]{2}{*}{ Sr. } & \multirow[t]{2}{*}{ Compound } & \multicolumn{3}{|c|}{$\begin{array}{c}\text { Tested microorganism } \\
\text { diameter of inhibition zone (mm) }\end{array}$} \\
\hline & & A. niger & A. flavous & A. alternate \\
\hline 1 & $\mathrm{C}_{20} \mathrm{H}_{17} \mathrm{NO}$ & $4 \pm 0.575$ & $4.15 \pm 0.570$ & $6.5 \pm 1.725$ \\
\hline 2 & $\mathrm{C}_{26} \mathrm{H}_{22} \mathrm{~N}_{2}$ & $4.5 \pm 1.915$ & $7.15 \pm 0.977$ & $8.55 \pm 0.015$ \\
\hline 3 & $\mathrm{C}_{26} \mathrm{H}_{24} \mathrm{~N}_{4}$ & $8.70 \pm 0.950$ & $9.55 \pm 0.977$ & $10.5 \pm 2.150 *$ \\
\hline 4 & $\mathrm{C}_{34} \mathrm{H}_{22} \mathrm{~N}_{2} \mathrm{O}$ & $9.15 \pm 0.815$ & $10.25 \pm 0.55^{*}$ & $10.5 \pm 0.575^{*}$ \\
\hline 5 & Standard & $24 \pm 0.550$ & $24.5 \pm 1.065$ & $23.5 \pm 0.955$ \\
\hline
\end{tabular}

Literature verifies that the delocalization of $\pi$ electrons over the whole molecule increases its lipophilicity which facilitates the penetration of such molecule into lipid membranes and hence restricting further proliferation of the fungi ${ }^{14}$. In another study it was found that $\pi$-electrons delocalization increases lipophilicity of the compound and increases permeation through the lipid layer of the bacterial membranes and hence enhances antimicrobial activity ${ }^{15}$.

Similarly it was reported that many Schiff bases are known to be medicinally important and used to design medicinal compounds ${ }^{5}$. Later, it was observed that some Schiff bases have high antimicrobial potential than other ${ }^{4}$. Literature also explains that the different antimicrobial response of the synthesized Schiff base arise because of their structure difference and the concentration use ${ }^{16}$. It was also reported that the Schiff base derived from aromatic aldehydes, having extensive conjugation are effective antimicrobial agents ${ }^{17}$. 


\section{ACKNOWLEDGEMENTS}

The financial support for research from GC University Faisalabad Pakistan is highly appreciated.

\section{REFERENCES}

1. T.D. Chaudhari and S.S. Subnis, Bull. Haffkine, 4, 85 (1986).

2. S. Shah, R. Vyas and R.H. Mehta, J. Indian Chem. Soc., 69, 590 (1992).

3. K. Sahu, R.K. Behera, R.C. Pathaik, A. Nayak and G.B. Behera, Indian J. Chem., 18B, 557 (1979).

4. M. Abdul-Gawad, Y.M. Issa and S.M. Abd-Alhamid, Egypt. J. Pharm. Sci., 34, 219 (1993).

5. S.A. Khan, A.A. Siddiqui and S. Bhatt, Asian J. Chem., 14, 117 (2002).

6. A. Elmali, M. Kabak and Y. Elerman, J. Mol. Struct., 477, 151 (2000).

7. S.N. Pandeya, D. Sriram, G. Nath and E. Declercq, Eur. J. Pharm., 9, 25 (1999).

8. R. Mladenova, M. Ignatova, N. Manolova, T. Petrova and I. Rashkov, Eur. Polym. J., 38, 989 (2002).

9. P. Singh, R.L. Goel and B.P. Singh, J. Indian Chem. Soc., 52, 958 (1975).
10. D. Singh, K. Kumar, S.S. Dhiman and J. Sharma, J. Enzyme Inhib. Med. Chem., 25, 21 (2010).

11. A.D. Logu, V. Onnis, B. Saddi, C. Congiu, M.L. Schivo and M.C. Cocco, J. Antimicrob. Chemother., 49, 275 (2002).

12. M. Cuenca-Estrella, B. Ruiz-Diez, J.V. Martinez-Suarez, A. Monzon and J.L. Rodriguez-Tudela, J. Antimicrob. Chemother., 43, 149 (1999).

13. M. Akbar, F. Naser and K. Mehdi, Turk. J. Chem., 34, 367 (2010).

14. A.A. Al-meiry, Y.K. Al-majedy, H.A. Ibrahim and A.A. Al-Tamimi, Org. Med. J., 2, 4 (2012).

15. M.R. Karekal, V. Biradar and M. Bennikallu Hire Mathada, Bioinorg. Chem. Appl., Article ID 315972, (2013).

16. X. Xiao, W. Jiag-Thao and B. Jie, J. Chem. Engr. Chinese Univ., 4, 160 (2010).

17. J. Sunny, J. Anil, G. Avneet and Hemraj, Asian J. Pharm. Clin. Res., 5, 199 (2012). 